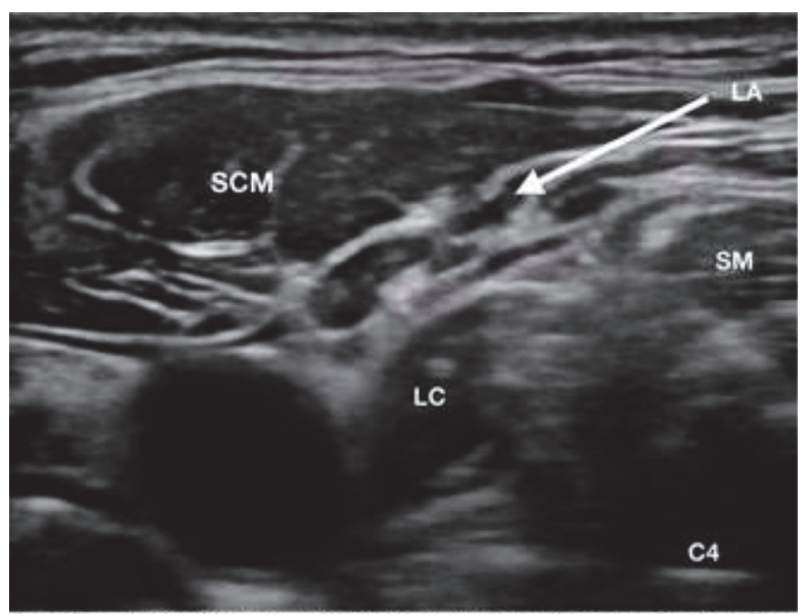

Abstract 18 Figure 1 Transverse sonogram of the lateral cervical area at the C4 level. The posterior cervical space is located between the sternocleidomastoid (SCM), longus colli (LC) and scalene (SM) muscles. Solid white arrow indicates the needle location for intermediate cervical plexus block where local anaesthetic (LA) spreads towards the carotid sheath

vessel angiogram demonstrating worsening of stenosis in the left proximal cervical segment of internal carotid artery. An ultrasound-guided Intermediate $\mathrm{CPB}$ was performed with Ropivacaine $0.4 \% 10 \mathrm{~mL}$ via a BBraun Stimuplex 22G $50 \mathrm{~mm}$ insulated needle preoperatively (figure 1). The patient opted for a general anaesthesia for the surgery. Intraoperative course was uneventful during both cross clamping of the carotid artery and internal carotid artery shunting.

Results Postoperatively, the patient was conscious, oriented, pain-free with no focal neurological deficits. The patient was monitored in surgical intensive care unit for a day and discharged to the ward.

Conclusions We demonstrated the Intermediate CPB to be feasible, effective and safe with low perioperative complications. Further studies are still required to explore this technique, including dose-finding studies to achieve optimum analgesia.

\section{ULTRASSOUND-GUIDED INFRAZYGOMATIC MAXILLARY NERVE BLOCK: AN ALTERNATIVE APPROACH TO MAXILLOFACIAL SURGERY - A CASE REPORT}

${ }^{1}$ GS Sousa* , ${ }^{2}$ A Vaz. 'Anesthesiology Resident from Centro Hospitalar Tondela-Viseu, Viseu, Portugal; ${ }^{2}$ Assistant of Anesthesiology from Centro Hospitalar Tondela-Viseu, Viseu, Portugal

\subsection{6/rapm-2021-ESRA.19}

Background and Aims Nose surgical procedures are associated with moderate postoperative pain, being the first 24 hours the most intense pain period. A lower level of postoperative pain promotes better healing, decreases anxiety and increases patient's comfort. Multimodal analgesia approach should be applied in order to provide maximum comfort while avoiding opioids adverse effects such as postoperative nausea and vomiting (PONV). PONV risk is exacerbated due to a passive blood flow that reaches the stomach during procedure. ${ }^{2}$ We report a case of an infrazygomatic maxillary nerve block (IZMNB) as part of multimodal analgesia for rhinoplasty surgery.
We intend to increase awareness to IZMNB as an effective analgesic technique for maxillofacial surgery.

Methods Case report and literature review.

Results A 28-year-old patient, ASA II, was admitted for a rhinoplasty and mentoplasty. Under general anesthesia, an ultrasound-guided IZMNB was performed bilaterally with ropivacaine $0.1 \%, 5 \mathrm{cc}$ each side, as part of a multimodal analgesic technique. Paracetamol and cetorolac were also administered. After emergence, patient referred low level of pain, needing only $2 \mathrm{mg}$ of morphine at the post-anesthetic care unit, due to chin pain (glossopharyngeal nerve area).

Conclusions IZMNB mechanism of action relies on local anesthetic dispersion within the pterygopalatine fossa. The

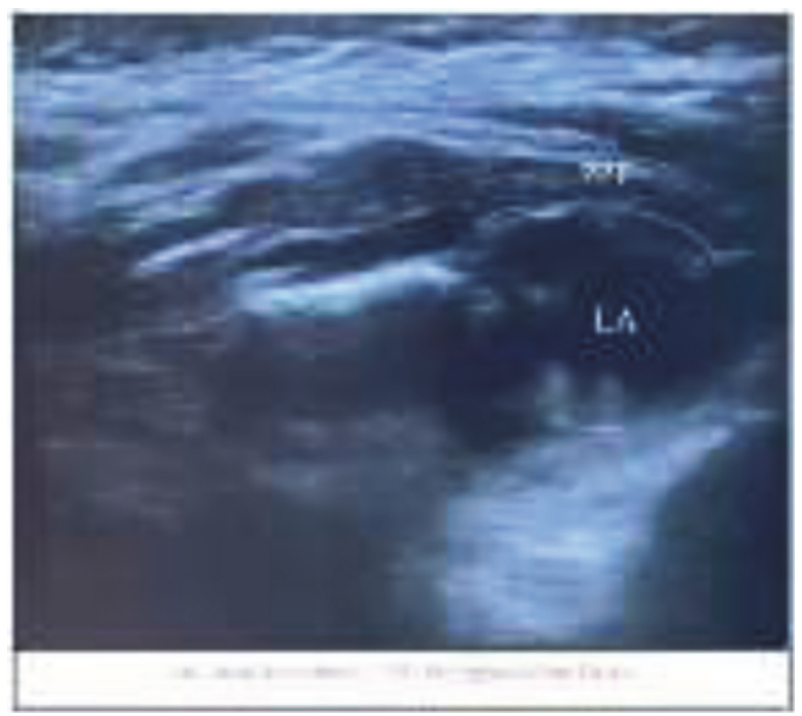

Abstract 19 Figure 1

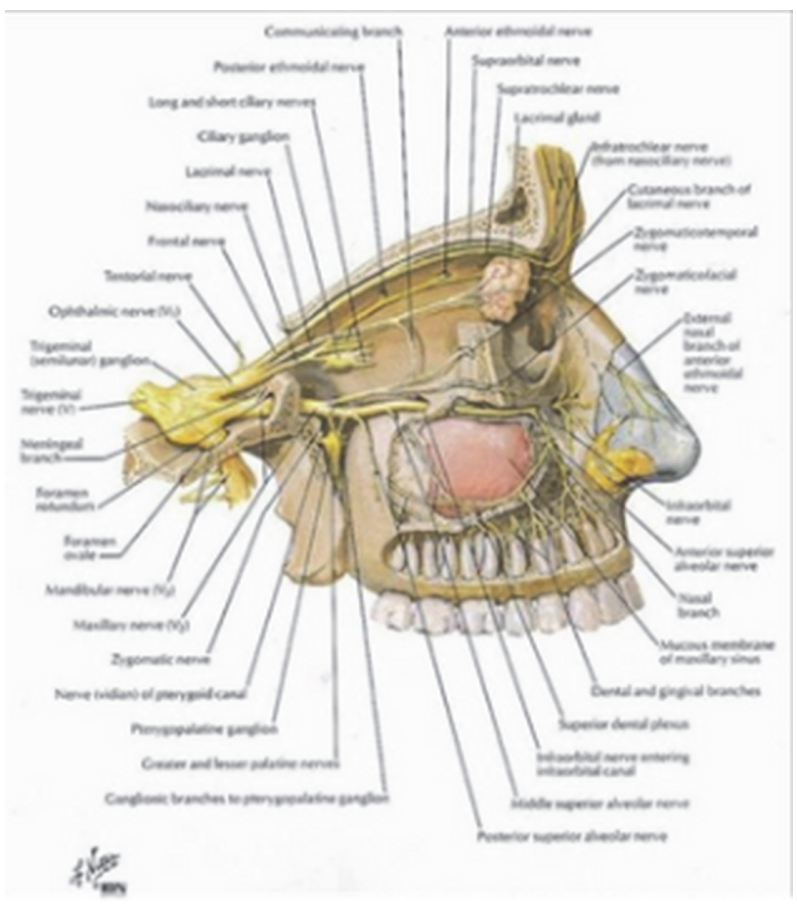

Abstract 19 Figure 2 
maxillary nerve block (second branch of the trigeminal nerve), at pterygopalatine fossa level, promotes effective analgesia to the middle third of the face.

\section{0 'THE ANALGESIC PLANE' FOR POSTERIOR CERVICAL SPINE FUSION SURGERIES}

BT Arish*, RV Ranjan, S Segaran, B Hariharasudan. Pondicherry Institute of Medical Sciences, Puducherry, India

\subsection{6/rapm-2021-ESRA.20}

Background and Aims Posterior C spine fusion surgeries will lead to severe post-operative pain arising from tissue trauma which affects the physiological functions of circulation and respiration as well as seriously affects early activities. We share our experience in this 4 cases which were managed with erector spinae along with GA which was effective during perioperative period.

Methods After informed written consent all 4 patients were anaesthetised by using standard general anaesthesia protocol and positioned prone. High frequency US probe (FUJIFILM SONOSITE M TURBO) placed over the transverse process of C7 (case 1), T1 (case 2), T2 (case $3 \& 4$ 4) to identify the erector spinae muscles (ESM). Using $23 \mathrm{G}$ quincke needle, by

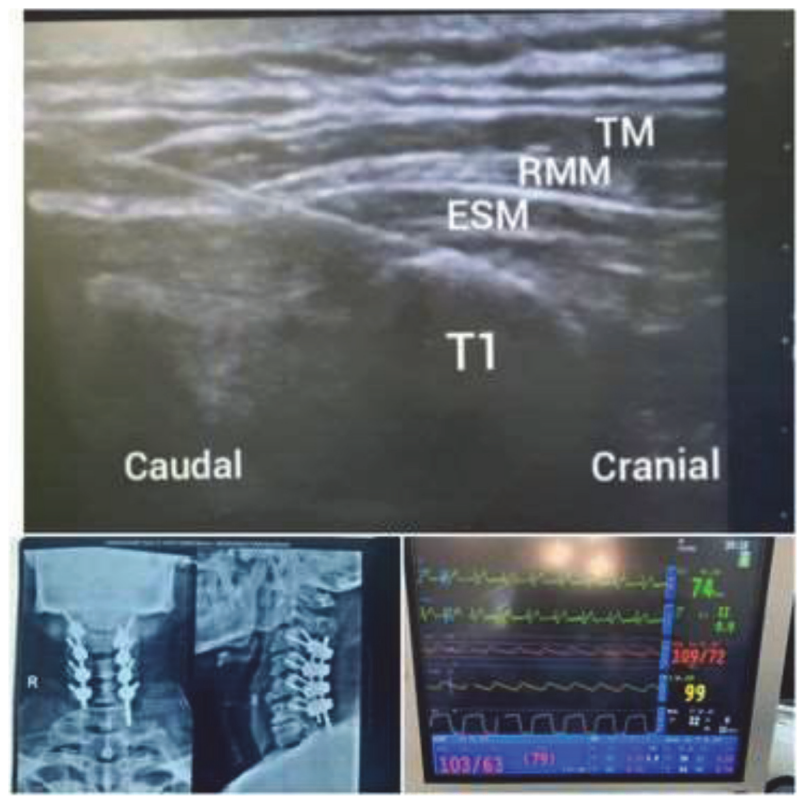

Abstract 20 Figure 1

Abstract 20 Table 1 Demographic data

\begin{tabular}{|c|c|c|c|c|}
\hline & Case 1 & Case 2 & Case 3 & Case 4 \\
\hline Age / sex & $67 / \mathrm{M}$ & $72 / \mathrm{M}$ & $38 / \mathrm{M}$ & $51 / \mathrm{M}$ \\
\hline BMI & 22 & 40 & 24.2 & 26 \\
\hline Co Morbidities & NIL & HTN, DM, OSA & $\begin{array}{c}\text { Smoker, } \\
\text { alcoholic }\end{array}$ & NIL \\
\hline $\begin{array}{c}\text { ASA physical } \\
\text { status }\end{array}$ & I & III & II & I \\
\hline Surgical level & C3-C6 & C3-C6 & C5-C7 & C3-C7 \\
\hline CESP & C7 & T1 & T2 & T2 \\
\hline $\begin{array}{c}\text { Surgical } \\
\text { duration }\end{array}$ & 240 mins & 270 mins & 270 mins & 300 mins \\
\hline
\end{tabular}

Abstract 20 Table 2

\begin{tabular}{|c|c|c|c|c|}
\hline & Case 1 & Case 2 & Case 3 & Case 4 \\
\hline $\begin{array}{c}\text { Additional Intra op } \\
\text { opioids use }\end{array}$ & NIL & NIL & NIL & NIL \\
\hline $\begin{array}{c}\text { Time of post op } \\
\text { opioid requirement }\end{array}$ & $12^{\text {th }} \& 22^{\text {nd }} \mathrm{hr}$ & $16^{\text {th }} \& 24^{\text {nd }} \mathrm{hr}$ & $14^{\text {th }} \mathrm{hr}$ & $14^{\text {th }} \& 20^{\text {th }} \mathrm{hr}$ \\
\hline $\begin{array}{c}\text { Total dose of opioid } \\
\text { consumption in the } \\
\text { post op (mg) }\end{array}$ & $50+50$ & $50+50$ & 50 & $50+50$ \\
\hline $\begin{array}{c}\text { Post op } \\
\text { complications }\end{array}$ & NIL & NIL & NIL & NIL \\
\hline
\end{tabular}

in plane approach the needle tip was placed between ESM and the transverse process. After confirmation with saline, B/L CESPB was given $(15 \mathrm{ml}$ of $0.25 \%$ bupivacaine $+4 \mathrm{mg}$ dexamethasone) on each side. Inj. paracetamol $15 \mathrm{mg} / \mathrm{kg}$ was given before skin incision and continued $6^{\text {th }}$ hourly for $1^{\text {st }} 24$ hrs post op. All patients hemodynamics were monitored. Postoperative pain was assessed using VAS score every hour for the $1^{\text {st }} 12$ hours and $2^{\text {nd }}$ Hourly till 24 hours. Inj tramadol $50 \mathrm{mg}$ was used for breakthrough pain (VAS score $\geq 4$ ) in the post op.

Results No additional opioids were requried during intra op peroid

Reduced post op opioid requirements

Promotes early mobilization

Conclusions We found CESPB provides an excellent site specific intra op and post-op analgesia and reduces the perioperative opioid requirements; thereby promotes early mobilization and hospital discharge.

\section{CONTINUOUS THORACIC PARAVERTEBRAL BLOCK FOR SIMPLE MASTECTOMY IN A PATIENT WITH MULTIPLE COMORBIDITIES - A CASE REPORT}

S Soni*, A Roy, D Mukherjee, A Das. Nil Ratan Sircar Medical College and Hospital, Kolkata, India

\subsection{6/rapm-2021-ESRA.21}

Background and Aims Anesthetic management in patients with multiple comorbidities is challenging for anesthesiologists.

Aim: To highlight the role of continuous thoracic paravertebral block (TPVB) for providing effective anesthesia and analgesia in breast surgery.

Methods A 63 years old female with uncontrolled hypertension, hypothyroid and coronary artery disease ( LVEF 26\%, NYHA Class III ) was scheduled for urgent simple mastectomy for Phylloides tumour of the right breast. Ultrasound guided continuous thoracic paravertebral block was performed at T4 level administering $20 \mathrm{ml}$ of $0.75 \%$ ropivacaine bolus followed by $0.2 \%$ ropivacaine infusion. Intraoperative sedation was maintained with dexmedetomidine infusion. $0.2 \%$ ropivacaine infusion at $5 \mathrm{ml} / \mathrm{hr}$ was continued for $48 \mathrm{hrs}$, after that catheter was removed.

Results Continuous TPVB provided adequate anesthesia, good hemodynamic stability and opioid sparing perioperative analgesia.

The VAS score in postoperative period at rest was 2/10 and on movement was 3/10.

There were no block related complications.

Conclusions Continuous thoracic paravertebral block is quite effective for breast surgery with comparative efficacy but lesser complications than general anesthesia. 